\title{
Topology and pressure distribution reconstruction of an englacial channel
}

\author{
Laura Piho, ${ }^{1, *}$, Andreas Alexander ${ }^{2, *}$, and Maarja Kruusmaa ${ }^{1,3}$ \\ ${ }^{1}$ Centre for Biorobotics, Tallinn University of Technology, Tallinn, Estonia \\ ${ }^{2}$ Department of Geosciences, University of Oslo, Oslo, Norway \\ ${ }^{3}$ Centre for Autonomous Marine Operations and Systems, Norwegian University of Science and Technology, Trondheim, \\ Norway \\ ${ }^{*}$ These authors contributed equally to this work.
}

Correspondence: Andreas Alexander (andreas.alexander@geo.uio.no)

\begin{abstract}
Glacier hydrology describes water movement over, through and under glaciers and ice sheets. Water reaching the ice bed influences ice motion and ice dynamical models, therefore requiring a good understanding of glacier hydrology, particularly water pressures and pathways. However, as in situ observations are sparse and methods for direct observations of water pathways and internal pressures are lacking, our understanding of the aforementioned pathways and pressure remains limited. Here, we present a method that allows the reconstruction of planar subsurface water flow paths and spatially reference water pressures. We showcase this method by reconstructing the 2D topology and the water pressure distribution of an englacial channel in Austre Brøggerbreen (Svalbard). The approach uses inertial measurements from submersible sensing drifters and reconstructs the flow path between given start and end coordinates. Validation on a supraglacial channel shows an average length error of $3.9 \mathrm{~m}(5.3 \%)$. At the englacial channel, the average length error is $107 \mathrm{~m}(11.6 \%)$ and the average pressure error $3.4 \mathrm{hPa}(0.3 \%)$. Our method allows mapping sub- and englacial flow paths and the pressure distribution within, thereby facilitating hydrological model validation. Further, our method also allows the reconstruction of other, previously unexplored, subsurface fluid flow paths.
\end{abstract}

\section{Introduction}

Water movement through and under glaciers and ice sheets in en- and subglacial drainage systems is an essential factor in the control of ice dynamics (Hubbard and Nienow, 1997; Fountain and Walder, 1998; Irvine-Fynn et al., 2011). Such systems vary in space and time, and their configuration is traditionally inferred using the physical principles (Röthlisberger, 1972) and concepts of hydraulic potential (Shreve, 1972) developed 50 years ago (see review by Flowers (2015)). Despite field observations challenging these concepts (e.g. Gulley et al., 2012), they are still widely used in many models (e.g. Pälli et al., 2003; Willis et al., 2009; Livingstone et al., 2013). Direct observations to validate such hydrological models are sparse, increasing their uncertainty, and recent approaches have therefore utilized Bayesian inversion modeling to fit hydrological models to sparse observations (Brinkerhoff et al., 2021; Irarrazaval et al., 2021). These approaches, however, still require field data (Brinkerhoff et al., 2021), which are hard to obtain. 
Time-consuming geophysical investigation methods, utilizing ground penetrating radar (GPR) (e.g. Stuart et al., 2003; Bælum and Benn, 2011; Hansen et al., 2020; Schaap et al., 2020) and seismic arrays (Gimbert et al., 2016; Nanni et al., 2020) are used to locate en- and subglacial channels. In wintertime, moulins and meltwater channels are accessible for direct speleological investigations and mapping of water flow paths in shallow glaciers (e.g. Holmlund, 1988; Vatne, 2001; Gulley et al., 2009; Alexander et al., 2020b; Hansen et al., 2020). Water pressures can either be inferred utilizing seismic arrays (Nanni et al., 2020) or measured directly via moulins and boreholes (e.g. Iken, 1972; Iken and Bindschadler, 1986; Engelhardt et al., 1990; Hubbard et al., 1995; Stone and Clarke, 1996; Vieli et al., 2004; Andrews et al., 2014), but those measurements are point-scale by nature (Flowers, 2015). Therefore, developing remote sensing methods that retrieve drainage parameters over problem-relevant spatial scales is critical to reducing the uncertainty in glacier and ice sheet models (Flowers, 2015, 2018).

In recent years submersible drifters have been used to measure water pressures along the flow path of glacial drainage systems (Bagshaw et al., 2012, 2014; Alexander et al., 2020a). Since global positioning with satellite systems is not possible in subsurface environments, the data recorded by these platforms are not spatially referenced. We have previously demonstrated high repeatability of measurements from inertial measurement units (IMUs), alongside pressure recordings in a supraglacial channel (Alexander et al., 2020a). An IMU unit contains accelerometers, gyroscopes, and magnetometers along and around all 3 axis of the device. In theory, double integration of the recorded IMU acceleration data would result in the traveled distance. In practice, error accumulation and noise lead to high uncertainty, a common problem in navigation, known as a dead-reckoning error (Montello, 2005). In mobile robotics, this problem is often addressed using probabilistic mapping algorithms (Thrun et al., 1998). Uncertainty is further reduced by using salient features, recognizable by sensors, as landmarks (Thrun, 1998). In this study, we use machine-learning extracted features from IMU data as salient features for mapping (Fourati et al. (2013)).

In our previous study (Alexander et al., 2020a) we observed distinct signal patterns related to the morphology of glacial channels but could not quantify and classify them to extract salient flow features. Here, we solve this problem using an infinite hidden Markov model Rabiner and Juang (1986) giving the probability distribution of features from IMU data. We further propose piece-wise integration of this data to compute the flow path between the extracted features. As such, the accumulated integration errors do not grow unbounded. As a result, we obtain a probabilistic 2D track of the channel between two known globally referenced points (e.g., Global Navigation Satellite System (GNSS) referenced deployment and recovery points). Measuring pressure along with the IMU data further allows spatial referencing of the pressure distribution along this track.

\section{Materials and Methods}

50 We showcase the feasibility and applicability of our approach with the reconstruction of the spatially referenced flow path and the water pressure distribution of an englacial channel on Austre Brøggerbreen, Svalbard. The 2D reconstructions are based on data collected by a submersible drifter platform containing an IMU as well as pressure sensors and compared to GNSS data gathered by a GNSS surface drifter on the open parts of the path. The results are also validated by the reconstruction of a supraglacial channel with respect to GNSS reference. We further qualitatively compare our englacial reconstruction to the 
https://doi.org/10.5194/tc-2021-377

Preprint. Discussion started: 6 January 2022

(c) Author(s) 2022. CC BY 4.0 License.

\section{(c) (i)}

results of an earlier GPR investigation (Stuart et al., 2003), satellite imagery, as well as to a GNSS reference recorded after the englacial channel had melted out one year later (table 1).

\subsection{Drifter platforms}

Two different drifter platforms were used in this study: A submersible drifter for path reconstruction and a GNSS surface drifter for reference measurements.

A detailed description of the submersible drifter can be found in Alexander et al. (2020a). The device is a $12 \mathrm{~cm} \mathrm{long,} 4$ $\mathrm{cm}$ diameter and $0.14 \mathrm{~kg}$, neutrally buoyant tube (fig. 1(a)-1(d)). It contains three $200 \mathrm{kPa}$ pressure sensors (MS5837-2BA, TE Connectivity, Switzerland) with a sensitivity of $2 \mathrm{~Pa}$ and a 9 degree of freedom (DOF) IMU (BNO055, Bosch Sensortec, Germany). The sampling rate for the pressure sensors and the IMU is $100 \mathrm{~Hz}$. All data are stored at a $16 \mathrm{~GB}$ microSD card in hexadecimal format.

The GNSS surface drifter, described in more detail in Tuhtan et al. (2020), served as reference. It is a $0.35 \mathrm{~kg}$ heavy, positively buoyant drifter consisting of a $20 \mathrm{~cm}$ long foam float enclosing a waterproof box (fig. 1(e)-1(h)). Inside the box is a custom-built printed circuit board (PCB) containing a Bosch BNO055 IMU and a NEO-M8T GNSS receiver powered by two rechargeable lithium batteries (type 1865, 3.7 V, $3600 \mathrm{mAh}$ ). All measurements are stored to an $8 \mathrm{~GB}$ microSD card at a sampling rate of $5 \mathrm{~Hz}$ in a hexadecimal format. The static positioning accuracy of the GNSS is $\pm 3 \mathrm{~m}$ in the horizontal and \pm 10 $\mathrm{m}$ in the vertical direction.

\subsection{Study site and fieldwork}

The fieldwork was conducted in July 2019 on Austre Brøggerbreen, an approximately $5 \mathrm{~km}$ long valley glacier located on the Svalbard archipelago (fig. 2). The glacier is entirely cold-based and thus characterized by low annual flow velocities (HAGEN and SÆTRANG, 1991). Several englacial channels exist and have been studied regularly over the past 20 years (Vatne, 2001; Stuart et al., 2003; Vatne and Irvine-Fynn, 2016; Kamintzis et al., 2018).

Our fieldwork focused on the lower englacial channel, which was mapped 20 years earlier and described by Vatne (2001) and Stuart et al. (2003). This channel is located close to the glacier snout, which is subject to rapid down-wasting. As a result the channel was close to the glacier surface in 2019 and completely melted out in 2020, compared to a depth within the ice of approximately 50 meters in 1999 (Vatne, 2001; Stuart et al., 2003). A small supraglacial channel further upstream of the glacier was further utilized for GNSS validation.

In order to test and validate our reconstruction algorithms, both drifter platforms were deployed in the small supraglacial channel on 02 Jul. 2019 between 12:00 - 18:00. Both platforms were then deployed into the englacial channel via a former moulin (fig. 2) on 05 Jul. 2019 between 12:00 - 18:00, during the period of the main spring snowmelt. All drifters were recovered by hand from a river in the glacier forefield. We revisited the englacial channel on 19 Aug. 2020 and deployed a GNSS enabled surface drifter to gather a GNSS path of the now melted-out channel. Table 1 summarizes the reconstruction cases, validation methods, and the number of drifter deployments for each experiment. 
https://doi.org/10.5194/tc-2021-377

Preprint. Discussion started: 6 January 2022

(c) Author(s) 2022. CC BY 4.0 License.

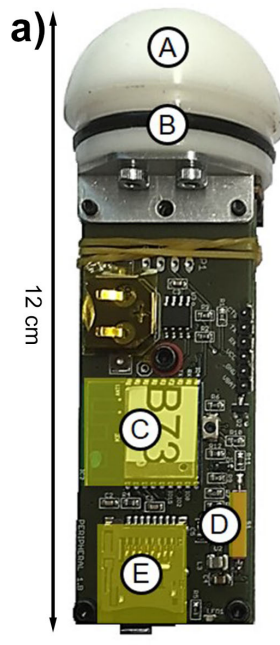

b)

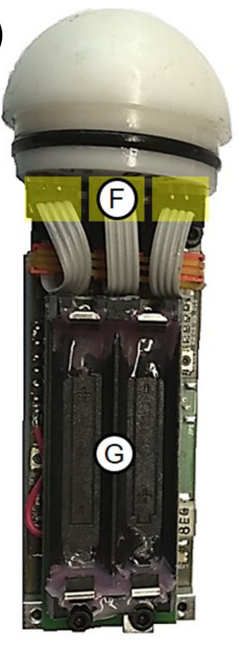

c)

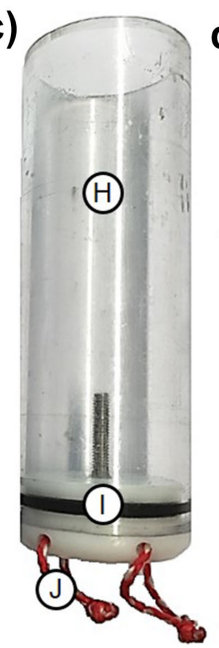

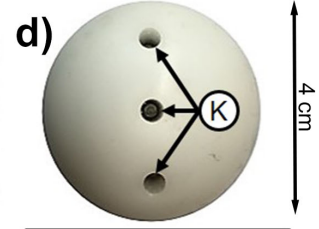

(A) Top Endcap

(B) O-ring

(C) $\mathrm{WiFi}$

(D) Magnetic Switch

(E) MicroSD

(F) Pressure Sensors

(G) Battery Holder

(1) Tube Housing

(1) Bottom Endcap

(1) Atttachment Strings

() Pressure Ports e)

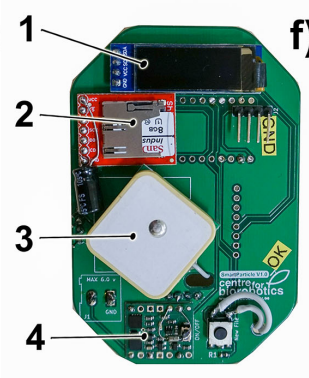

f)

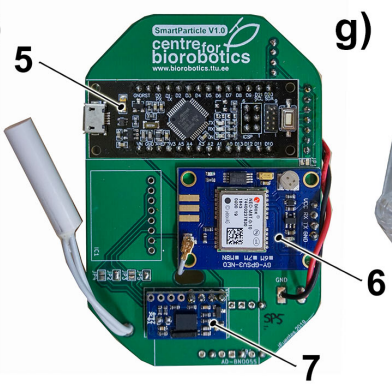

g)

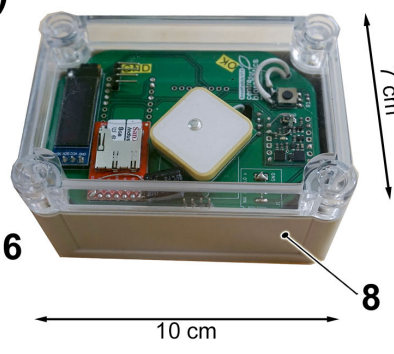

h)

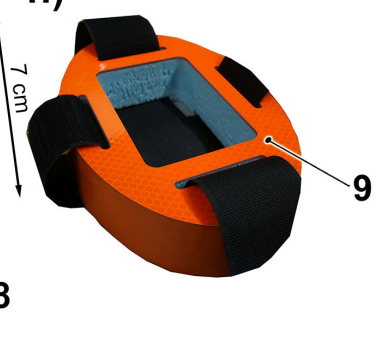

\section{1: LCD screen 2: microSD module 3: GNSS antenna 4: Power controller 5: Microcontroller 6: u-blox m8T (GNSS module) 7: IMU 8: IP68-cover 9: Buoyant floater}

Figure 1. Two different drifter platforms have been used in this study: A submersible drifter (a)-(d) and a GNSS surface drifter (e)-(h). (a) Side view showing the submersible drifter electronics. (b) Side view showing the reverse side of the electronics board including the battery holder and pressure sensors. (c) Polycarbonate tube housing of the submersible drifters with attachment strings for balloons used for manual buoyancy adjustment. (d) Top view facing the cap, showing the ports for each of the three pressure sensors. (e) Side view showing the GNSS surface drifter electronics with LCD screen SD storage, GNSS antenna and power controller. (f) Side view showing the reverse side of the GNSS surface drifter electronics with mirocontroller, GNSS receiver and IMU. (g) The electronics of the GNSS surface drifter are sealed in a waterproof box. (h) The box gets placed at the center of a $20 \mathrm{~cm}$ long float. 


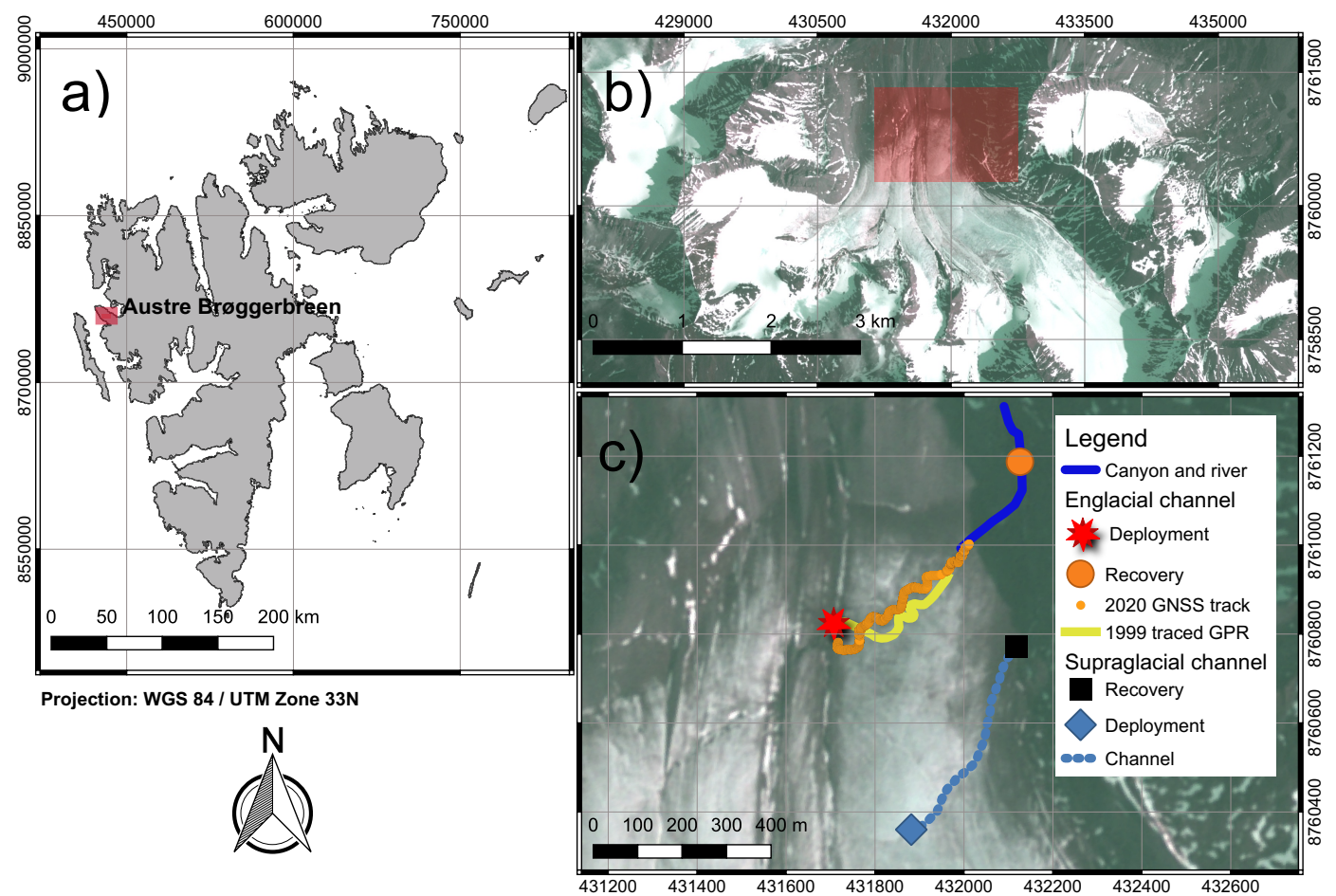

Figure 2. The test site. (a) Location of Austre Brøggerbreen on the Svalbard archipelago. (b) Location of the investigated supra- and englacial channel on the glacier. Background image: Planet Labs, 09 Jul. 2019 (Team Planet, 2017). (c) Map of the studied supra- and englacial channel with flow directions (blue arrows). Shown are the 2019 GNSS track with deployment and recovery point for the supraglacial channel, the 1999 GPR track of the englacial channel from Stuart et al. (2003), the 2020 GNSS track of the melted out englacial channel, as well as river and canyon section following the englacial channel, mapped out from Planet optical imagery (Team Planet, 2017). Additionally shown are the deployment and recovery points used for drifter deployments at the englacial channel. Background image: Planet Labs, 09 Jul. 2019 (Team Planet, 2017).

Table 1. Overview of the reconstruction cases, the validation methods and the number of submersible drifter deployments as well as the number of complete submersible drifter datasets.

\begin{tabular}{c|c|c|c}
\hline \multicolumn{2}{c|}{ Reconstruction } & Validation \\
\hline Channel type & \# of deployments & \# of complete data & Reference for validation \\
\hline Supraglacial channel & 18 & 11 & GNSS surface drifter \\
\hline Englacial channel & 16 & 6 & 1999 GPR track \\
& & & 2019 planet imagery \\
& & 2020 GNSS drifter (partial reference from the open section) \\
\hline
\end{tabular}


https://doi.org/10.5194/tc-2021-377

Preprint. Discussion started: 6 January 2022

(c) Author(s) 2022. CC BY 4.0 License.
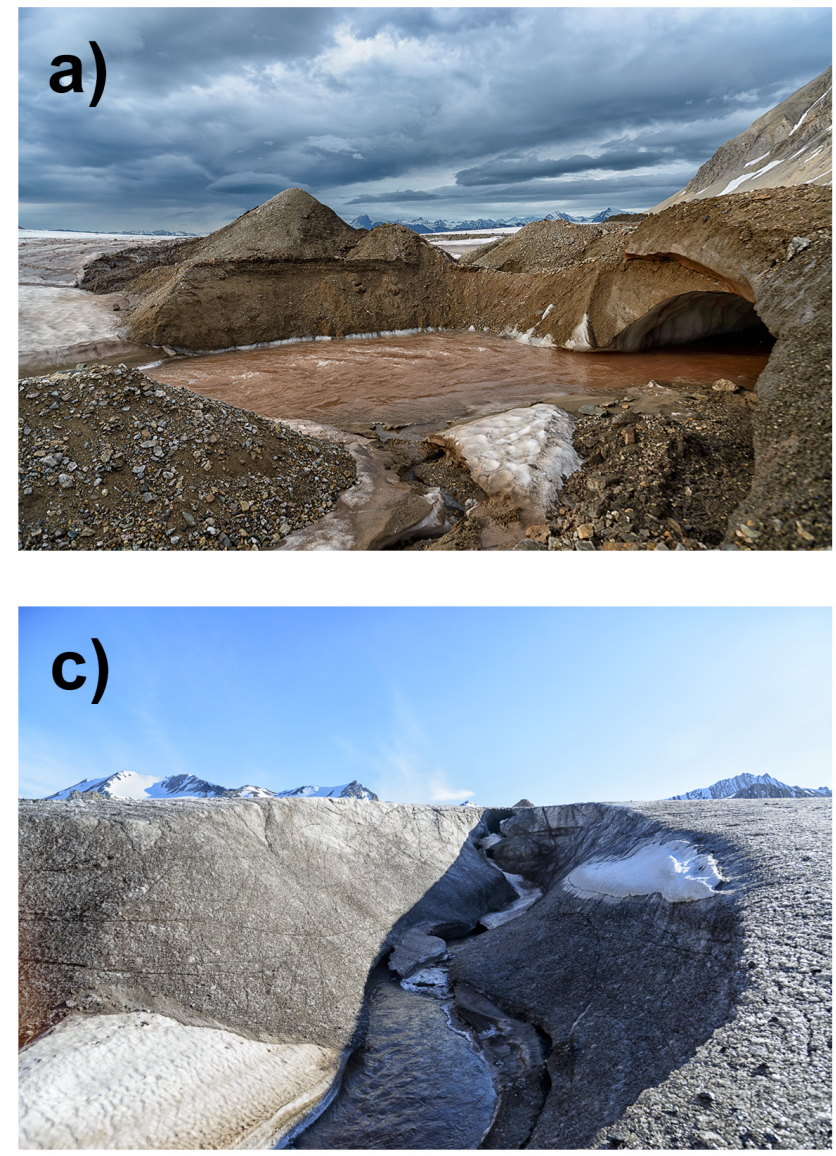

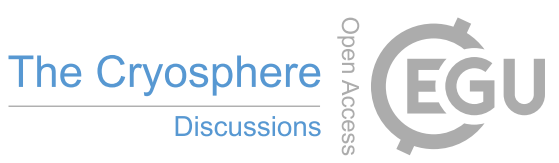
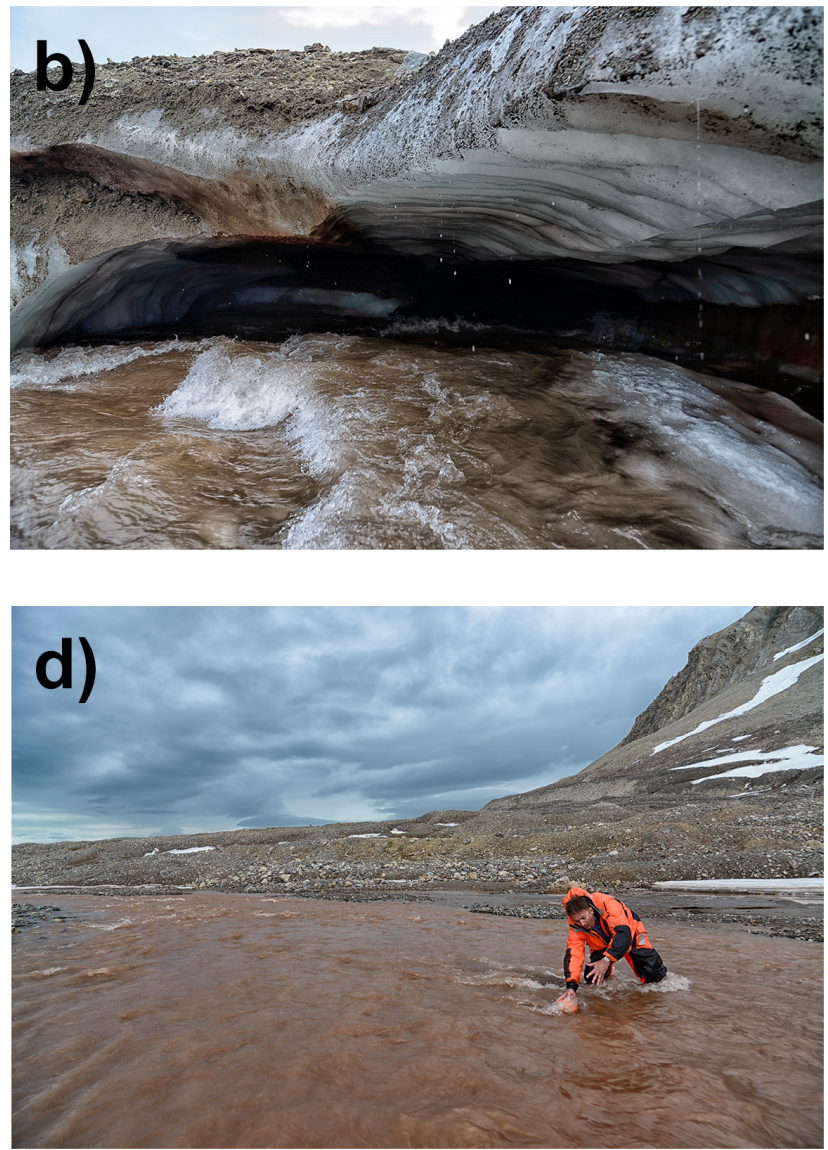

Figure 3. Pictures from the field deployments in July 2019. (a) Deployment point at the englacial channel. (b) Entrance to the englacial channel. (c) Canyon following the outlet of the englacial channel. (d) Drifter recovery at the proglacial river. 
https://doi.org/10.5194/tc-2021-377

Preprint. Discussion started: 6 January 2022

(c) Author(s) 2022. CC BY 4.0 License.

(c) (i)

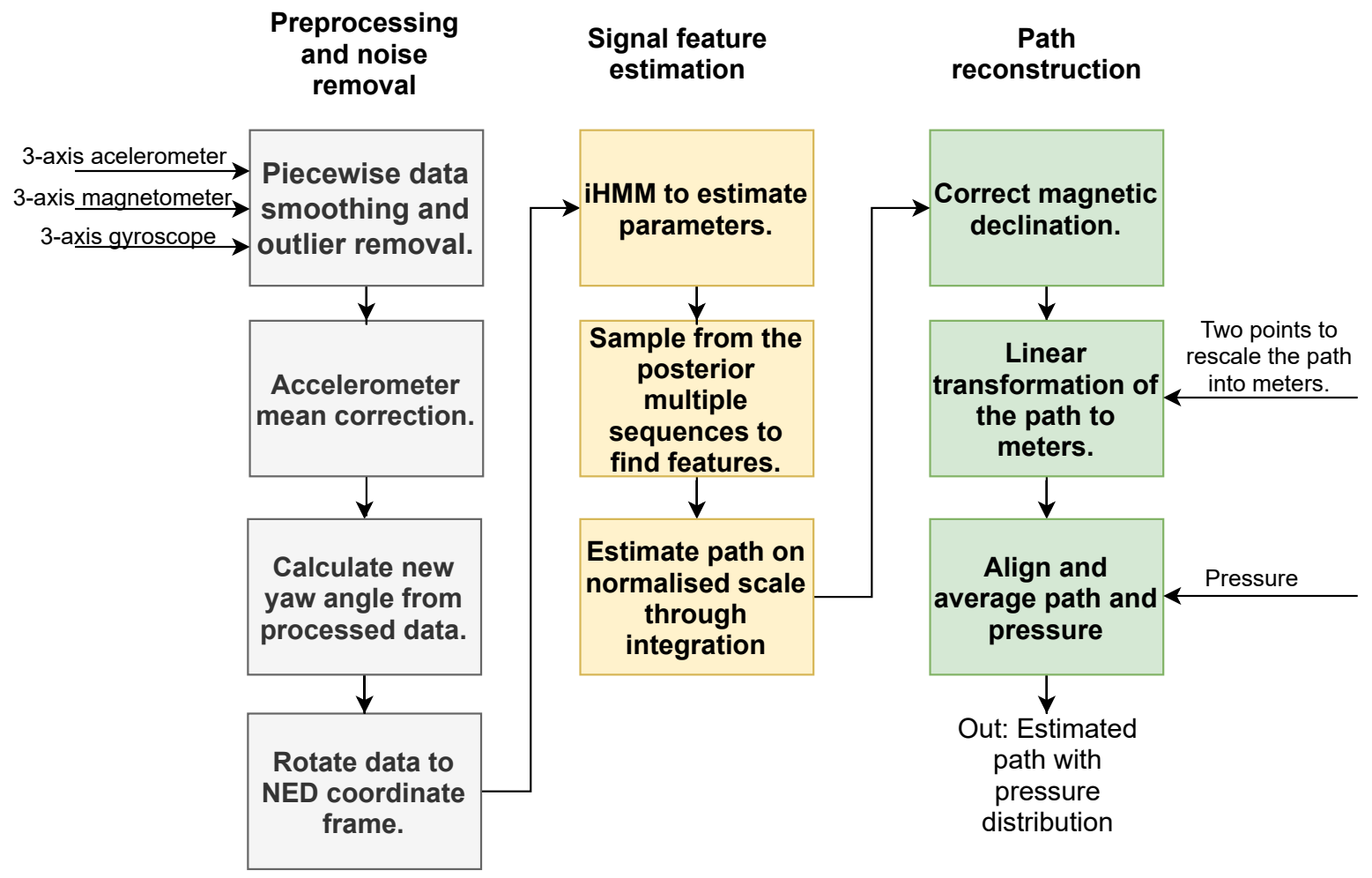

Figure 4. Workflow diagram of the processing sequence. The model applies an infinite hidden Markov model (iHMM) on the IMU data to detect signal features.

\subsection{Model description}

The general workflow of our subsurface flow path reconstruction is shown in fig. 4. The input data for the noise removal and feature extraction phases are the gyroscope, acceleration, and magnetometer readings of the submersible drifter's IMU.The IMUs used provide internally calculated quaternions as well as Euler angles (Diebel, 2006), providing information about the device orientation. The output of the model is the average 2D flow path in UTM coordinates (WGS84 UTM 32 North) with pressure distribution.

For flow path reconstruction, additional input is needed to specify the start and end points of the path. In our case, those are GNSS referenced deployment and recovery coordinates of the drifters. The processing and modeling of drifter data from one deployment took on average 20 minutes. For this, we used MATLAB 2019b on a consumer laptop (1.8 GHz Intel Core i7, 8 GB RAM). 


\subsection{Preprocessing and noise removal}

The data from each submersible drifter deployment were manually clipped to consider only the time between deployment and recovery. Each deployment dataset consisted of multiple repeated measurements of 9 DOF IMU sensor data (3-axis accelerometer, 3-axis magnetometer, and 3-axis gyroscope) at $100 \mathrm{~Hz}$, and readings from three pressure sensors.

In order to obtain an accurate orientation estimation, the IMU data were piecewise filtered, outliers removed, and a mean correction applied to the accelerometer data. For this, the data was split up where the mean of the signals changed significantly (Killick et al., 2012). The subdivision of the data was followed by removing noise from each section separately, without over-smoothing the rest of the path. A first-order Savitzky-Golay filter (Savitzky and Golay, 1964) was then applied to both accelerometer and magnetometer data in each section to remove high-frequency noise. This filter was chosen as it preserved high-frequency signal components better than other commonly used filters. Afterward, outliers were manually removed using a variance based outlier filter with a 1-2 $\sigma$ threshold, depending on the amount of noise in the signal. Abrupt changes in the acceleration behavior lead to significant errors in the rotation calculation and hence considerable jumps in the reconstructed path. To smooth these jumps, we applied a component-wise mean correction on the acceleration data. For this, we calculated the mean along the whole flow path and each individual section. We then computed the average between the total flow path mean and each section mean and set this average as the new mean for each section.

The data were rotated into a Cartesian north-east-down (NED) coordinate system, using the pitch and roll angles from the device and the yaw angle calculated from the processed accelerometer and magnetometer readings. The data were down sampled from $100 \mathrm{~Hz}$ to $25 \mathrm{~Hz}$ by decimating the signal by a factor 4 to increase the model's processing speed.

\subsubsection{Estimating the signal features using infinite hidden Markov model}

Hidden Markov models (HMM) are unsupervised learning models in which the state is not fully observable, instead it is only observed indirectly via some noisy observations (Rabiner and Juang, 1986). In this study, the noisy observations are the IMU derived accelerometer, magnetometer, and gyroscope signals. Using HMM, the aim is to find the hidden states (features), which are assumed to be associated with velocity. Similarly, to Fourati et al. (2013), at the beginning of each feature (e.g. meanders), the component-wise velocity is assumed to be zero (or close to zero).

First, consider a finite (regular) HMM that takes the measured IMU signals, denoted by $\mathbf{y}=\left\{y_{1}, y_{2}, \ldots, y_{T}\right\}$ as input (observation sequence), and finds the hidden state sequence $\mathbf{s}=\left\{s_{1}, s_{2}, \ldots, s_{T}\right\}$, which, in the scope of this paper, is assumed to be the velocity features of the water flow in the channel (e.g. step-pool sequences, meander bends). In finite HMM, each state takes a value from a finite number of states $1, \ldots, K$, which have to be predefined. A transition matrix $\pi$ describes the probabilities of moving between states. The probability of moving from state $i$ at time $t$ to state $j$ at time $t+1$ is given as $\pi_{i j}=p\left(s_{t}=i \mid s_{t+1}=j\right)$ and the initial probabilities are given by $\pi_{0 i}=p\left(s_{1}=i\right)$. In addition, there exists $\phi_{s_{t}}$ for each state $s_{t} \in\{1, \ldots, K\}$, that parametrizes the observation likelihood for that state given by $y_{t} \mid s_{t} \sim F\left(\phi_{s_{t}}\right)$. The observation likelihood describes the probability of an observation $y_{t}$ being generated from a state. Hence, the HMM can be written as $\left\{\pi_{0}, \boldsymbol{\pi}, \boldsymbol{\phi}, K\right\}$. The joint distribution over hidden states $\mathbf{s}$ and observations $\mathbf{y}$, given the parameters $\left\{\pi_{0}, \boldsymbol{\pi}, \boldsymbol{\phi}, K\right\}$, can be written as: 
The finite HMMs have two limitations: First, maximum likelihood estimations do not consider the complexity of the model. This makes underfitting and overfitting hard to avoid. Second, the model has to be specified in advance. This means, that even though the hidden states are unknown, the number of different states has to be predefined. Due to the complexity of the model, predefining it is difficult, as one has to choose the number of different features in the glacial channels based only on the measured IMU data.

We address these limitations by applying an infinite hidden Markov model (iHMM) (Beal et al., 2002). The iHMM uses Dirichlet processes to define a non-parametric Bayesian analysis on HMM, allowing a countably infinite number of hidden states, thus permitting automatic determination of the number of hidden states. Therefore, not knowing how many different features are present in the glacial channel is not a problem anymore. In a HMM, the transition matrix $\pi$ is a $K \times K$ matrix, where $K$ is predefined. In iHMM, by contrast $K \rightarrow \infty$. To allow this and to complete the Bayesian description, the priors are defined using hierarchical Dirichlet processes (HDP), allowing to have distributions over hyper-parameters and making the model more flexible.

The HDP are a set of Dirichlet processes (DP) coupled through a shared random base measure drawn from a DP. That is, each $G_{k} \sim \operatorname{DP}\left(\alpha, G_{0}\right)$ with a shared base measure $G_{0}$ and a concentration parameter $\alpha>0$. The shared base measure can be thought of as the mean of $G_{k}$ and the concentration parameter $\alpha$ controls the variability around $G_{0}$. In addition, the shared base measure is also given a DP prior $G_{0} \sim \mathrm{DP}(\gamma, H)$, where $H$ is a global base measure. The formal definition of the iHMM is given as:

$$
\begin{aligned}
\beta & \sim \operatorname{GEM}(\gamma) \\
\pi_{k} \mid \beta & \sim \operatorname{DP}(\alpha, \beta) \\
\phi_{k} & \sim H \\
s_{t} \mid s_{t-1} & \sim \operatorname{Multinomial}\left(\pi_{s_{t-1}}\right) \\
y_{t} \mid s_{t} & \sim F\left(\phi_{s_{t}}\right) .
\end{aligned}
$$

Where $\mathrm{DP}(\alpha, \beta)$ is a $\mathrm{DP}$, the parameter $\beta$ is a hyperparameter for the DP that is distributed according to the stick-breaking construction noted as Griffiths, Engen, and McCloskey's distribution GEM(.) (Sethuraman, 1994). The indicator variable $s_{t}$ is sampled from the multinomial distribution. Finally, priors are also put on hyperparameters $\alpha$ and $\gamma$. As there are no strong beliefs about the hyperparameters, a common practice is to use gamma hyperpriors.

To find the two sets of unknowns, i.e., the hidden states and the hyperparameters, Beam sampling (Van Gael et al., 2008) is used. The Beam sampling combines slice sampling and dynamic programming, where the first limits the number of states considered at each time step to a finite number, and the second samples the hidden states efficiently. 


\subsubsection{Path reconstruction}

As a result, a posterior probability over sequences of observations has been found, and multiple possible velocity feature (hidden state) sequences are sampled from the posterior distribution. This results in a set of possible sequences of flow features along the glacial path. The path estimation is performed for multiple feature sequences. Hence, creating multiple possible paths and an estimated region of error.

The integration is done in two steps. Assuming that the component-wise velocity is zero at the beginning of each feature, the first integration is calculated over each feature separately, setting the component velocity to zero at the beginning. This results in a velocity profile that does not correspond to the real velocity values along the path; however, it describes the changes in velocity along the path. The second integration is performed over the new velocity profile and normalized, resulting in the glacier water flow path topology map on a normalized scale. After correcting for magnetic declination, the resulting topology map can be rescaled back to Earth coordinates through a linear transformation. This transformation can be found by knowing two distinct points along the path, in our case, the deployment and recovery positions. The reconstructed paths from each deployment and their pressure distributions are aligned and averaged. The alignment was thereby performed using dynamic time warping (Sakoe and Chiba, 1978), such that each subsequent signal was aligned with the mean of previous signals. Overall this resulted in the pressure distribution and estimated average reconstruction of the hydrological flow path.

\section{Results}

\subsection{Supraglacial reconstruction and validation}

We tested our approach with the reconstruction of a supraglacial channel with known geometry (fig. 2(c)). As a reference, we used an averaged path (table 1), derived from GNSS surface drifter measurements. We calculated the position error for each point on the reconstructed path as

Error $=\sqrt{\left(p_{x}(t)-\hat{p}_{x}(t)\right)^{2}+\left(p_{y}(t)-\hat{p}_{y}(t)\right)^{2}}$

where $p_{x}(t)$ and $p_{y}(t)$ are the coordinates measured via GNSS and $\hat{p}_{x}$ and $\hat{p}_{y}$ are the estimated points from the reconstruction. The reconstruction was based on 11 submersible drifter deployments. Our model reproduces a flow path, which is within 3.9 $\mathrm{m}$ of the GNSS reference path (fig. 5). The lowest position error is thereby $2.0 \mathrm{~m}$, and the most significant deviation from the reference path is $11.1 \mathrm{~m}$, based on the average of 10 nearest points. As fig. 6 shows, the average position error from our reconstruction converges after 6 datasets (one drifter deployment needed per dataset). The total length of the GNSS reference track is $449 \mathrm{~m}$, whereas the reconstructed path is $478 \mathrm{~m}$ long, equal to an overestimation by $6.5 \%$. The resulting flow path allows to reference the pressure measurements of the drifters spatially. The resulting pressure distribution map shows the pressure variations along the channel. Zones of higher pressures occurred mainly in the lower part of the channel as the drifters moved from a higher elevation down to lower elevation and in areas where the channel changes direction. 
https://doi.org/10.5194/tc-2021-377

Preprint. Discussion started: 6 January 2022

(c) Author(s) 2022. CC BY 4.0 License.

(c) (i)

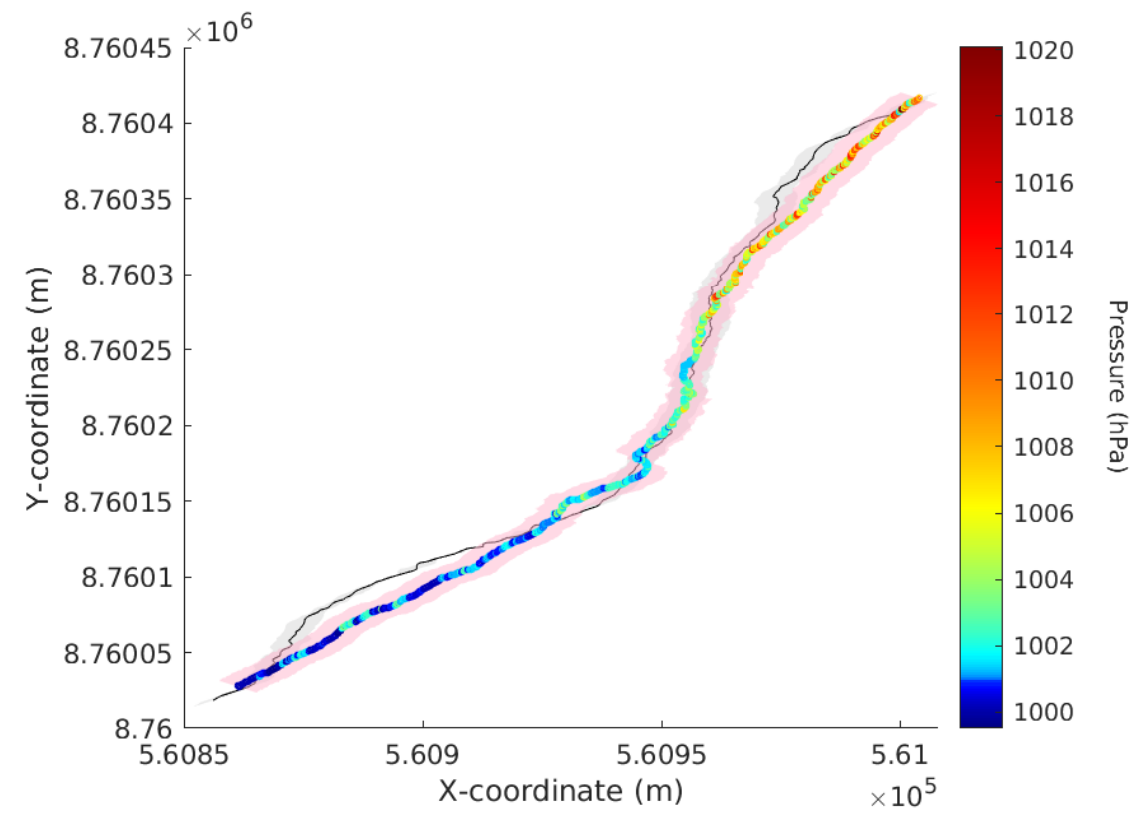

(a)

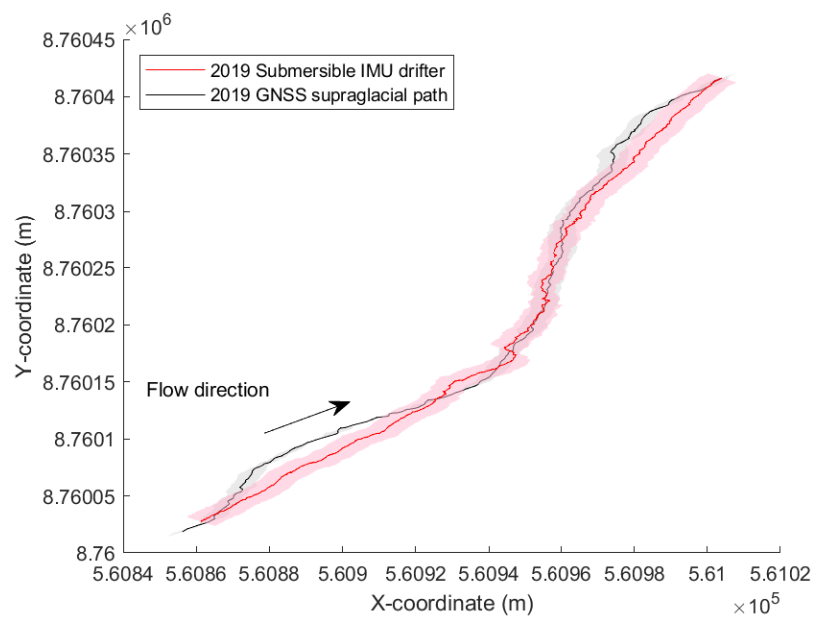

(b)

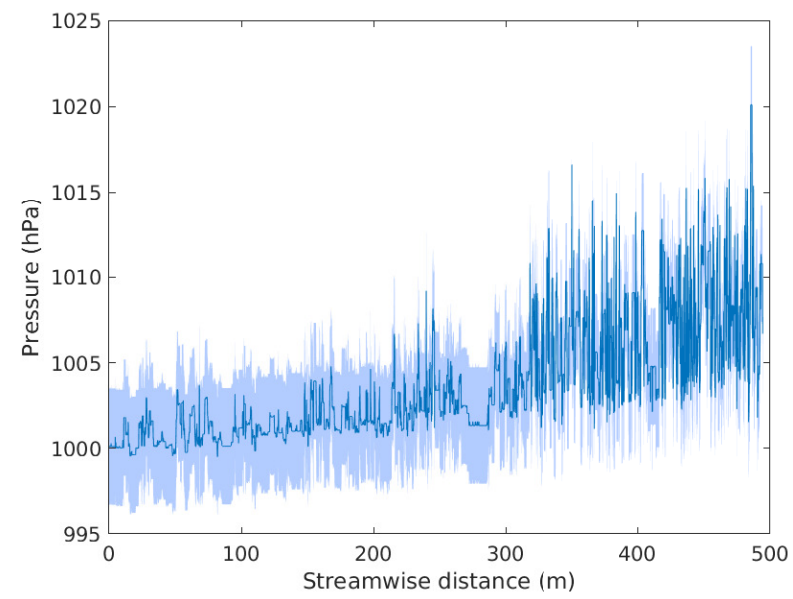

(c)

Figure 5. Supraglacial path reconstruction. (a) Reconstructed supraglacial track in UTM coordinates with pressure distribution in hPa. (b) Estimation of the supraglacial track (red) with standard deviations (pink) in UTM coordinates. The GNSS reference is shown in black and the average error of the GNSS recordings in light gray. The deployment and recovery points are denoted with green and blue circles respectively. The arrow denotes the flow direction. (c) Average water pressure with standard deviation along the estimated stream-wise distance of the supraglacial channel. 


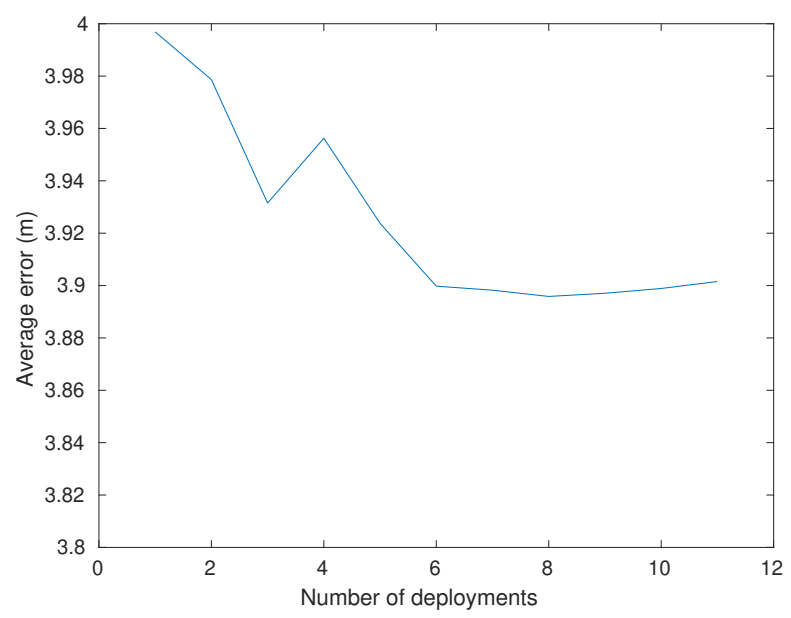

Figure 6. Convergence of the average error for the supraglacial channel reconstruction with respect to the number of deployments.

\subsection{Englacial channel reconstruction and validation}

The submersible drifter deployments for the reconstruction were conducted in July 2019. A revisit of the field site in August 2020 allowed us to map the flow path of the channel with the GNSS surface drifter, as the roof of the channel had mostly melted away and transformed the former englacial channel into a deeply incised supraglacial channel, which was only partly ice-covered. The reconstruction from the IMU data, collected in 2019 (6 datasets), leads to the mean flow path shown in fig. 7(b). The figure also shows the comparison between a GNSS reference track measured one year later in summer 2020 and a GPR measurement from 1999. The shape of the reconstructed flow path thereby resembles the shape of both, the 2020 GNSS reference and the 1999 GPR track from (Stuart et al., 2003).

The overall average position error (based on equation 7) of the reconstructed englacial channel and the proglacial river, compared to the 2020 GNSS reference path for the channel, as well as the 2019 satellite derived proglacial river path (fig. 7), is $12.1 \mathrm{~m}$. The englacial channel part of the reconstruction has an average position error of $13.3 \mathrm{~m}$ compared to the 2020 GNSS reference (table 1 for an overview of used references). From the englacial outlet through the canyon (fig. 3(c)) and the proglacial river up to the recovery point (fig. 3(d)), the average position error of the reconstructed path is 10.9 m compared to the satellite reference path. The 2020 GNSS reference track (1 deployment) from the englacial channel has a length of $545 \mathrm{~m}$. The section after the outlet of the channel through the canyon and the proglacial river measures $290 \mathrm{~m}$ on the satellite imagery. Our model returns a total path length of $1027 \mathrm{~m}$ from deployment point to recovery point. The channel section is thereby 651 $\mathrm{m}$ long and the part through the canyon and the proglacial river $376 \mathrm{~m}$.

The mean pressure recorded by the drifters is $1011.7 \mathrm{hPa}$ with a standard deviation of $3.4 \mathrm{hPa}(0.3 \%)$. The spatial pressure distribution map (fig. 7(a)) reveals one zone of higher pressure shortly before the englacial channel exits into the open canyon. 
The average water pressure thereby reaches up to $1070 \mathrm{hPa}$, compared to maximum values of $1300 \mathrm{hPa}$ recorded by the submersible drifters before averaging.

The flow path of the englacial channel, investigated in this study, has been repeatedly mapped by previous studies. These studies offer additional reference paths to assess the feasibility of the reconstruction qualitatively. Stuart et al. (2003) utilized GPR to draw a map of the channel (shown in fig. 2(c)), whereas Vatne (2001) used speleological investigations, providing a very simple map in his publication.

The qualitative comparison between the 1999 GPR reconstruction of the englacial channel from Stuart et al. (2003) and our GNSS surface drifter measurements from 2020 show good accordance in the overall shape of the flow path. It is visible that the channel developed by both vertical and lateral incision, thereby keeping its overall shape over the 21 years spanning between the two investigations. The satellite reference used for the canyon (fig. 3(c)) and the proglacial river (fig. 3(d)) was mapped on planet imagery, which has a positional accuracy of less than $10 \mathrm{~m}$ root mean square error (Team Planet, 2017). The canyon was thereby barely visible on the imagery leading to a straight reference track instead of a meandering one. However, the sharp turn of the river after the canyon exit is visible on the satellite imagery and can be matched to the topology of the reconstructed path.

\section{Discussion}

We showed the topological reconstruction of a supra- and englacial channel on Austre Brøggerbreen (Svalbard). The motivation for this study was to provide in-situ measurements from englacial and supraglacial channels to inform hydrological models important for predictions of glacier dynamics. The contribution of this paper is a method for mapping subsurface flows using submersible drifters' IMU measurements and mapping the pressure readings of the sensors along the reconstructed path. The comparison with GNSS tracks (at open parts of the channels), as well as the comparison to the previous studies of the same englacial channel at Austre Brøggerbreen, provided quantitative and qualitative comparisons of the constructed path.

The path reconstructions were compared to the GNSS measurements at the open parts of the channels and revealed the average error of the length estimate of 5.3\% for the supraglacial and $11.6 \%$ for the englacial channel. However, it has to be noted that the GNSS reference used in the supraglacial channel reconstruction is not the most accurate. The static positioning error of the used GNSS receivers is $\pm 3 \mathrm{~m}$, with the dynamic positioning error, in a highly turbulent supraglacial stream, certainly much higher. The used GNSS reference path is additionally an aligned average of 26 single tracks, thereby over-smoothing several meander-bends and therefore smoothing the real channel geometry. An average error of $3.9 \mathrm{~m}$ for the reconstruction versus the GNSS reference path is therefore likely below the accuracy of the GNSS reference track itself. The over-smoothing of the GNSS reference path also explains, why the reconstructed path length is $6.5 \%$ longer compared to the section with available GNSS reference.

The flow path length of the englacial reconstruction is $1027 \mathrm{~m}$, much longer than the sum of the GNSS and the satellite reference path of $835 \mathrm{~m}$. However, the GNSS reference path is missing the first section of the englacial channel after deployment due to changed water pathways between 2019 and 2020. Based on handheld GPS measurements ( $\pm 5 \mathrm{~m}$ ), this length 
https://doi.org/10.5194/tc-2021-377

Preprint. Discussion started: 6 January 2022

(c) Author(s) 2022. CC BY 4.0 License.

(c) (i)

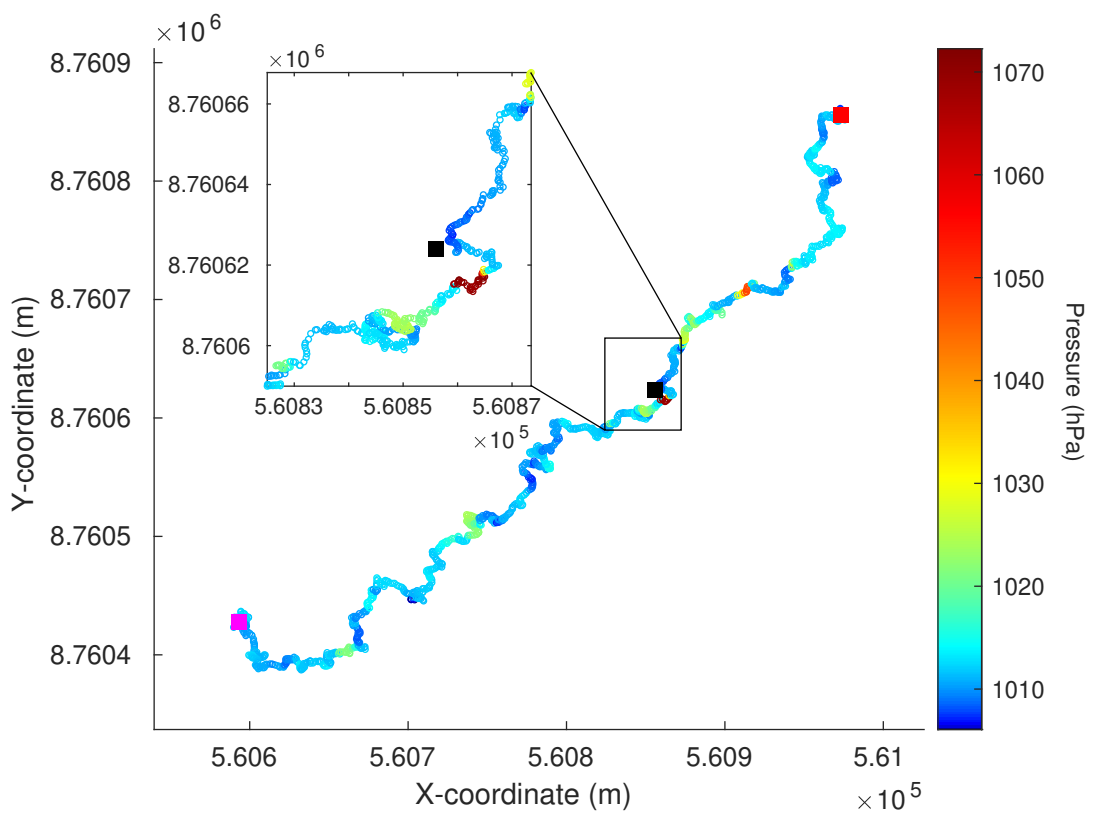

(a)

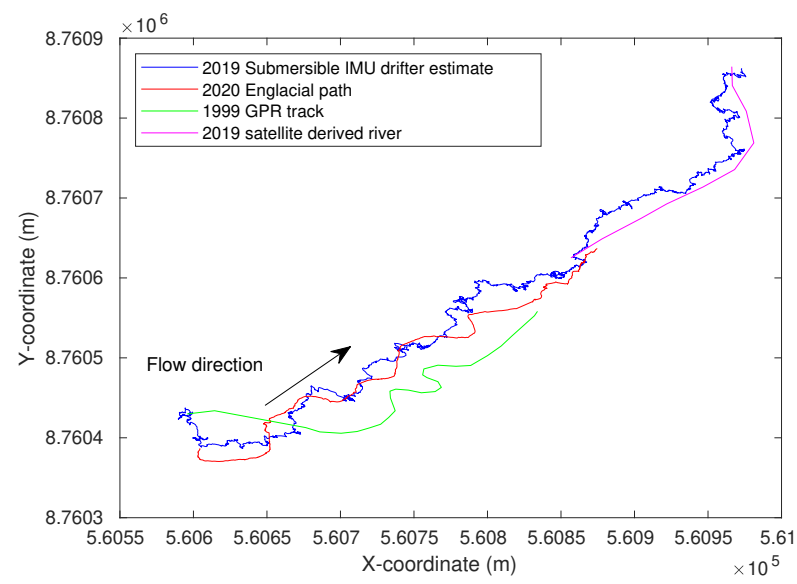

(b)

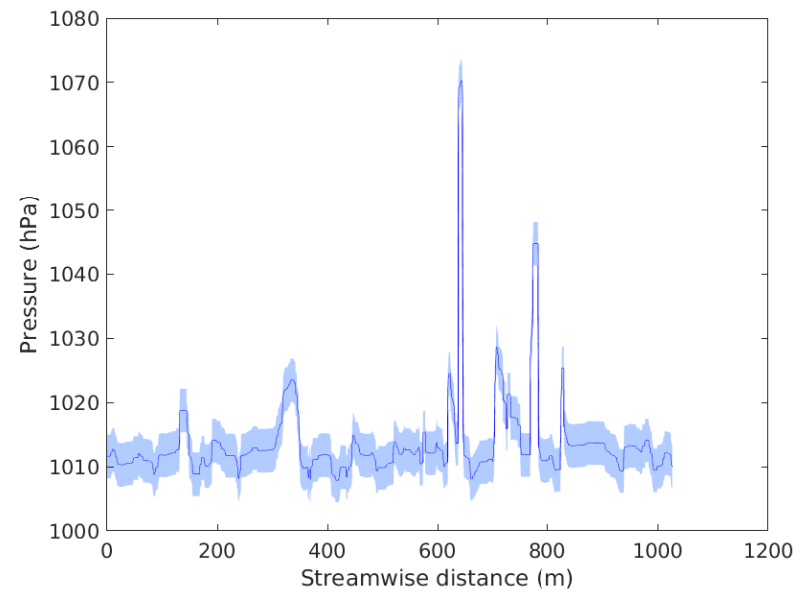

(c)

Figure 7. Englacial channel reconstruction. (a) Estimated average track of the englacial channel in UTM coordinates with pressure distribution in hPa. (b) Estimated englacial track in UTM coordinates based on the 2019 IMU data in blue alongside GNSS drifter reference measured in 2020 in red. Further shown are the mapped canyon and proglacial river from optical Planet imagery (acquisition date 09 Jul. 2019), (Team Planet, 2017)), as well as the 1999 GPR map traced from (Stuart et al., 2003). The Black square denotes the deployment point and the green square the recovery location. Additionally shown is the location of the start of the canyon at the end of the englacial channel (red square). (c) Average water pressure with standard deviation along the estimated stream-wise distance of the englacial channel. 
difference is estimated to be $85 \mathrm{~m}$. This leaves a difference of $107 \mathrm{~m}$ between reference track length and the reconstruction or an overestimation of the track by $11.6 \%$. This does not take into account that the satellite reference path is underestimating the real track length. Therefore, the real length error of our reconstruction is likely much lower. On the other hand, the drifter based reconstruction could also overestimate the channel length. Our reconstruction is based on the distance traveled by the drifters. As they can get stuck in eddies or travel from one side of the channel to the other, the reconstructed path becomes longer than the real channel. This can also be seen in very wobbly sections of the channel reconstruction in fig. 7(a).

The hydrological system of Austre Brøggerbreen has been studied several times in the past, and thus offers the possibility to evaluate the feasibility of our reconstruction. We have shown that some prominent features (large bends and step-pool sequences) reoccur between our reconstruction and previous studies. Glacier drainage systems do, however, evolve and change rapidly over the years. It is therefore impossible to establish if the discrepancies between our reconstruction and previous studies are due to an inaccurate reconstruction or can be attributed to the changes of the channel itself. Assuming the later would offer the opportunity to study the evolution of an englacial channel over a several decade long timespan.

The pressures recorded by the submersible drifters in the englacial channel show flow under atmospheric conditions. Pressurized flow conditions, with water flowing partly uphill as encountered by Stuart et al. (2003), no longer exist within the channel. The average error of the pressure data is, with $3.4 \mathrm{hPa}$, similar to our previous work (Alexander et al., 2020a), thus very low. Within the englacial channel itself, one zone of abrupt and high pressure change exists shortly before the channel exits into the canyon. Similar to pressure peaks studied in Alexander et al. (2020a), we interpret this as the presence of a step-pool sequence with a large step riser. This interpretation was confirmed by speleological investigations in 2018, where a roughly $2.5 \mathrm{~m}$ high step riser was found at the same location.

\section{Conclusions}

In this study, we used a relatively low number of deployments (11 for the supraglacial channel and 6 for the englacial channel) for the reconstruction with an average error of $3.9 \mathrm{~m}$ and $12.1 \mathrm{~m}$, respectively. The average error calculations for the supraglacial channel (fig. 6) show that the error converges at 6 deployments. The decrease of the average error with increasing deployment number is, however, so low (2.5\%) that a single deployment would already lead to sufficient precision. Using the values for the mean pressure and its standard deviation, leads to a precision of $0.66 \%$ with just one deployment, according to equation 4 in Alexander et al. (2020a). This shows that our approach can produce a highly precise topological reconstruction and spatial pressure distribution from just one deployment. As we have lost one submersible drifter out of 16 deployments at the englacial channel (93.8\% recovery rate) and encountered technical problems (e.g. drifter switched off during deployment, damaged pressure recordings) with quite some of the retrieved datasets (utility rate of only 40\%), we estimate that at least 3 submersible drifter deployments will be needed in the field in order to obtain the topology of an englacial channel.

At the current stage, we are only able to produce the planar topology of the flow path. A full 3D reconstruction was not possible as the IMUs did not correct for the gravity vector. Removing the gravity vector in the post-processing stage introduces additional uncertainty and therefore renders an inaccurate elevation track. We are, however, optimistic that we will be able to do 
https://doi.org/10.5194/tc-2021-377

Preprint. Discussion started: 6 January 2022

(c) Author(s) 2022. CC BY 4.0 License.

(c) (i)

full 3D reconstructions in an improved version of our method by collecting additional vertical reference data and accounting for the error introduced by the gravity vector. The current model is also not able to calculate the numerical velocity, as the model operates largely on a normalized space. Another development step will therefore be to reconstruct flow velocities utilizing the time stamp of the IMU recordings alongside the reconstructed path length. Mapping flow velocities alongside pressure distribution would provide additional input for numerical flow models.

Overall, we have developed a method that is able to produce decent flow path reconstructions with only two given coordinates. As our method can already be run with the data from just one submersible drifter deployment and on a consumer laptop, it will be practical for a variety of field applications. This suggests that our results might have significant implications, not only for glaciology, but also for subsurface flow studies in general.

Code and data availability. The source code developed for this manuscript is available via GitHub: https://github.com/LauraPiho/GlacierMapping

The data is available under DOI:10.5281/zenodo.4462823

Author contributions. A.A. and M.K. designed the study and conducted the fieldwork. L.P. processed data and developed the model. A.A. processed data and prepared the manuscript. All authors contributed to the manuscript and the interpretation of the data.

Competing interests. The authors have no competing interests to declare.

Acknowledgements. The fieldwork for this project was funded by the H2020 INTERACT Transnational Access project DeepSense 2019, University of Oslo Industrial Liason, University of Oslo Garpen Stipend, the Department of Geosciences University of Oslo, the Research Council of Norway funded MAMMAMIA project (grant number 301837 MAMMAMIA: Multi-scale multi-method analysis of mechanisms causing ice acceleration) and the Svalbard Environmental protection fund (17/31). This research was further funded by the European Research Council (grant no. ICEMASS) and the Research Council of Norway (grant no. 223254 - NTNU AMOS). Fieldwork in 2020 was funded by the Research Council of Norway via an Arctic Field Grant (2020/310689) and POLARPROG (2020/317905) to AA. This study is a contribution to the Svalbard Integrated Arctic Earth Observating System (SIOS). We further on acknowledge support from the team of the NPI Sverdrup station, particularly Vera Sklet, during the fieldwork. Asko Ristolainen and Astrid Tesaker helped during the 2020 field campaign. The drifters used in this study were originally designed by Jeffrey A. Tuhtan and Juan Francisco Fuentes-Pérez. We also acknowledge Jeffreys contribution during the 2019 fieldwork for this study and his valuable input for model development and scientific discussions. Input to the GNSS surface drifter figure was provided by Kerstin Alexander. Feedback from Mauro Werder, Gwenn Flowers and two anonymous reviewers helped to improve the quality of the manuscript. 
https://doi.org/10.5194/tc-2021-377

Preprint. Discussion started: 6 January 2022

(c) Author(s) 2022. CC BY 4.0 License.

(c) (P)

\section{References}

Alexander, A., Kruusmaa, M., Tuhtan, J. A., Hodson, A., Schuler, T., and Kääb, A.: Pressure and inertia sensing drifters for glacial hydrology flow path measurements, The Cryosphere, 14, 1009-1023, https://doi.org/10.5194/tc-14-1009-2020, 2020a.

Alexander, A., Obu, J., Schuler, T. V., Kääb, A., and Christiansen, H. H.: Subglacial permafrost dynamics and erosion inside subglacial channels driven by surface events in Svalbard, The Cryosphere, 14, 4217-4231, https://doi.org/10.5194/tc-14-4217-2020, 2020b.

Andrews, L. C., Catania, G. A., Hoffman, M. J., Gulley, J. D., Lüthi, M. P., Ryser, C., Hawley, R. L., and Neumann, T. A.: Direct observations of evolving subglacial drainage beneath the Greenland Ice Sheet, Nature, 514, 80-83, https://doi.org/10.1038/nature13796, 2014.

Bælum, K. and Benn, D. I.: Thermal structure and drainage system of a small valley glacier (Tellbreen, Svalbard), investigated by ground penetrating radar, The Cryosphere, 5, 139-149, https://doi.org/10.5194/tc-5-139-2011, 2011.

Bagshaw, E. A., Burrow, S., Wadham, J. L., Bowden, J., Lishman, B., Salter, M., Barnes, R., and Nienow, P.: E-tracers: Development of a low cost wireless technique for exploring sub-surface hydrological systems, Hydrological Processes, 26, 3157-3160, https://doi.org/10.1002/hyp.9451, 2012.

Bagshaw, E. A., Lishman, B., Wadham, J. L., Bowden, J. A., Burrow, S. G., Clare, L. R., and Chandler, D.: Novel wireless sensors for in situ measurement of sub-ice hydrologic systems, Annals of glaciology, 55, 41-50, https://doi.org/10.3189/2014AoG65A007, 2014.

Beal, M. J., Ghahramani, Z., and Rasmussen, C. E.: The infinite hidden Markov model, in: Advances in neural information processing systems, vol. 1, pp. 577-584, 2002.

Brinkerhoff, D., Aschwanden, A., and Fahnestock, M.: Constraining subglacial processes from surface velocity observations using surrogatebased Bayesian inference, Journal of Glaciology, p. 1-19, https://doi.org/10.1017/jog.2020.112, 2021.

Diebel, J.: Representing attitude: Euler angles, unit quaternions, and rotation vectors, Matrix, 58, 1-35, 2006.

Engelhardt, H., Humphrey, N., Kamb, B., and Fahnestock, M.: Physical conditions at the base of a fast moving Antarctic ice stream, Science, 248, 57-59, https://doi.org/10.1126/science.248.4951.57, 1990.

Flowers, G. E.: Modelling water flow under glaciers and ice sheets, Proceedings of the Royal Society A: Mathematical, Physical and Engineering Sciences, 471, https://doi.org/10.1098/rspa.2014.0907, 2015.

Flowers, G. E.: Hydrology and the future of the Greenland Ice Sheet, Nature Communications, 9, https://doi.org/10.1038/s41467-018-05002$0,2018$.

Fountain, A. G. and Walder, J. S.: Water flow through temperate glaciers, Reviews of Geophysics, 36, 299-328, https://doi.org/10.1029/97RG03579, 1998.

Fourati, H., Manamanni, N., Afilal, L., and Handrich, Y.: Position estimation approach by complementary filter-aided IMU for indoor environment, in: 2013 European Control Conference (ECC), pp. 4208-4213, IEEE, https://doi.org/10.23919/ECC.2013.6669211, 2013.

Gimbert, F., Tsai, V. C., Amundson, J. M., Bartholomaus, T. C., and Walter, J. I.: Subseasonal changes observed in subglacial channel pressure, size, and sediment transport, Geophysical Research Letters, 43, 3786-3794, https://doi.org/10.1002/2016GL068337, 2016.

Gulley, J., Grabiec, M., Martin, J., Jania, J., Catania, G., and Glowacki, P.: The effect of discrete recharge by moulins and heterogeneity in flow-path efficiency at glacier beds on subglacial hydrology, Journal of Glaciology, 58, 926-940, 2012.

335 Gulley, J. D., Benn, D. I., Screaton, E., and Martin, J.: Mechanisms of englacial conduit formation and their implications for subglacial recharge, Quaternary Science Reviews, 28, 1984-1999, https://doi.org/10.1016/j.quascirev.2009.04.002, 2009.

HAGEN, J. O. and SÆTRANG, A.: Radio-echo soundings of sub-polar glaciers with low-frequency radar, Polar Research, 9, 99-107, https://doi.org/https://doi.org/10.1111/j.1751-8369.1991.tb00405.x, 1991. 
https://doi.org/10.5194/tc-2021-377

Preprint. Discussion started: 6 January 2022

(c) Author(s) 2022. CC BY 4.0 License.

(c) (i)

Hansen, L. U., Piotrowski, J. A., Benn, D. I., and Sevestre, H.: A cross-validated three-dimensional model of an englacial and subglacial drainage system in a High-Arctic glacier, Journal of Glaciology, 66, 278-290, https://doi.org/10.1017/jog.2020.1, 2020.

Holmlund, P.: Internal geometry and evolution of moulins, Storglaciären, Sweden, Journal of Glaciology, 34, 242-248, https://doi.org/10.3189/S0022143000032305, 1988.

Hubbard, B. and Nienow, P.: Alpine subglacial hydrology, Quaternary Science Reviews, 16, 939-955, https://doi.org/10.1016/S02773791(97)00031-0, 1997.

345 Hubbard, B., Sharp, M. J., Willis, I. C., Nielsen, M., and Smart, C. C.: Borehole water-level variations and the structure of the subglacial hydrological system of Haut Glacier d'Arolla, Valais, Switzerland, Journal of Glaciology, 41, 572-583, https://doi.org/10.3189/S0022143000034894, 1995.

Iken, A.: Measurements of water pressure in moulins as part of a movement study of the White Glacier, Axel Heiberg Island, Northwest Territories, Canada, Journal of Glaciology, 11, 53-58, https://doi.org/10.3189/S0022143000022486, 1972.

Iken, A. and Bindschadler, R. A.: Combined measurements of subglacial water pressure and surface velocity of Findelengletscher, Switzerland: conclusions about drainage system and sliding mechanism, Journal of Glaciology, 32, 101-119, https://doi.org/10.3189/S0022143000006936, 1986.

Irarrazaval, I., Werder, M. A., Huss, M., Herman, F., and Mariethoz, G.: Determining the evolution of an alpine glacier drainage system by solving inverse problems, Journal of Glaciology, p. 1-14, https://doi.org/10.1017/jog.2020.116, 2021.

Irvine-Fynn, T. D. L., Hodson, A., Moorman, B. J., Vatne, G., and Hubbard, A. L.: Polythermal glacier hydrology: a review, Reviews of Geophysics, 49, https://doi.org/10.1029/2010RG000350, 2011.

Kamintzis, J. E., Jones, J. P. P., Irvine-Fynn, T. D. L., Holt, T. O., Bunting, P., Jennings, S. J. A., Porter, P. R., and Hubbard, B.: Assessing the applicability of terrestrial laser scanning for mapping englacial conduits, Journal of Glaciology, 64, 37-48, https://doi.org/10.1017/jog.2017.81, 2018.

Killick, R., Fearnhead, P., and Eckley, I. A.: Optimal detection of changepoints with a linear computational cost, Journal of the American Statistical Association, 107, 1590-1598, https://doi.org/10.1080/01621459.2012.737745, 2012.

Livingstone, S., Clark, C., Woodward, J., and Kingslake, J.: Potential subglacial lakes and meltwater drainage pathways beneath the Antarctic and Greenland ice sheets, The Cryosphere, 7, 1721-1740, 2013.

Montello, D. R.: Navigation., Cambridge University Press, https://doi.org/10.1017/CBO9780511610448.008, 2005.

365 Nanni, U., Gimbert, F., Vincent, C., Gräff, D., Walter, F., Piard, L., and Moreau, L.: Quantification of seasonal and diurnal dynamics of subglacial channels using seismic observations on an Alpine glacier, The Cryosphere, 14, 1475-1496, https://doi.org/10.5194/tc-14-1475$2020,2020$.

Pälli, A., Moore, J. C., Jania, J., and Glowacki, P.: Glacier changes in southern Spitsbergen, Svalbard, 1901-2000, Annals of Glaciology, 37, 219-225, 2003.

Rabiner, L. and Juang, B.: An introduction to hidden Markov models, ieee assp magazine, 3, 4-16, 1986.

Röthlisberger, H.: Water pressure in intra-and subglacial channels, Journal of Glaciology, 11, 177-203, https://doi.org/10.3189/S0022143000022188, 1972.

Sakoe, H. and Chiba, S.: Dynamic programming algorithm optimization for spoken word recognition, IEEE transactions on acoustics, speech, and signal processing, 26, 43-49, https://doi.org/10.1109/TASSP.1978.1163055, 1978.

375 Savitzky, A. and Golay, M. J. E.: Smoothing and differentiation of data by simplified least squares procedures, Analytical chemistry, 36, 1627-1639, 1964. 
https://doi.org/10.5194/tc-2021-377

Preprint. Discussion started: 6 January 2022

(c) Author(s) 2022. CC BY 4.0 License.

(c) (i)

Schaap, T., Roach, M. J., Peters, L. E., Cook, S., Kulessa, B., and Schoof, C.: Englacial drainage structures in an East Antarctic outlet glacier, Journal of Glaciology, 66, 166-174, https://doi.org/10.1017/jog.2019.92, 2020.

Sethuraman, J.: A constructive definition of Dirichlet priors, Statistica sinica, 4, 639-650, 1994.

Shreve, R. L.: Movement of water in glaciers, Journal of Glaciology, 11, 205-214, https://doi.org/10.3189/S002214300002219X, 1972.

Stone, D. B. and Clarke, G. K. C.: In situ measurements of basal water quality and pressure as an indicator of the character of subglacial drainage systems, Hydrological Processes, 10, 615-628, https://doi.org/10.1002/(SICI)1099-1085(199604)10:4<615::AIDHYP395>3.0.CO;2-M, 1996.

Stuart, G., Murray, T., Gamble, N., Hayes, K., and Hodson, A.: Characterization of englacial channels by ground-penetrating radar: An example from Austre Brøggerbreen, Svalbard, Journal of Geophysical Research: Solid Earth, 108, https://doi.org/10.1029/2003JB002435, 2003.

Team Planet: Planet application program interface: In space for life on Earth, https://api.planet.com, 2017.

Thrun, S.: Learning metric-topological maps for indoor mobile robot navigation, Artificial Intelligence, 99, 21-71, https://doi.org/10.1016/S0004-3702(97)00078-7, 1998.

Thrun, S., Burgard, W., and Fox, D.: A probabilistic approach to concurrent mapping and localization for mobile robots, Autonomous Robots, 5, 253-271, https://doi.org/10.1023/A:1008806205438, 1998.

Tuhtan, J. A., Kruusmaa, M., Alexander, A., and Fuentes-Pérez, J.: Multiscale change detection in a supraglacial stream using surface drifters, in: River Flow 2020, CRC Press, https://doi.org/10.1201/b22619-205, 2020.

Van Gael, J., Saatci, Y., Teh, Y. W., and Ghahramani, Z.: Beam sampling for the infinite hidden Markov model, in: Proceedings of the 25th international conference on Machine learning, pp. 1088-1095, https://doi.org/10.1145/1390156.1390293, 2008.

Vatne, G.: Geometry of englacial water conduits, Austre Brøggerbreen Svalbard, Norsk Geografisk Tidsskrift, 55, 85-93, https://doi.org/10.1080/713786833, 2001.

Vatne, G. and Irvine-Fynn, T.: Morphological dynamics of an englacial channel, Hydrology and Earth System Sciences, 20, 2947-2964, https://doi.org/10.5194/hess-20-2947-2016, 2016.

Vieli, A., Jania, J., Blatter, H., and Funk, M.: Short-term velocity variations on Hansbreen, a tidewater glacier in Spitsbergen, Journal of Glaciology, 50, 389-398, https://doi.org/10.3189/172756504781829963, 2004.

Willis, I., Lawson, W., Owens, I., Jacobel, B., and Autridge, J.: Subglacial drainage system structure and morphology of Brewster Glacier, New Zealand, Hydrological Processes: An International Journal, 23, 384-396, 2009. 